\title{
Prospective trial comparing the use of sulphasalazine and auranofin as second line drugs in patients with rheumatoid arthritis
}

\author{
D Porter, R Madhok, J A Hunter, H A Capell
}

\begin{abstract}
Two hundred patients with rheumatoid arthritis were studied in a prospective open trial comparing treatment with sulphasalazine and auranofin in patients with active disease over 12 months. The two drugs improved many parameters of disease activity at 12, 24, and 48 weeks. At 12 weeks, the group treated with sulphasalazine had a lower platelet count (Mann-Whitney U test), erythrocyte sedimentation rate, and articular index, with a greater decrease in erythrocyte sedimentation rate (Students $t$ test) and $C$ reactive protein between 0 and 12 weeks. There were no significant differences between sulphasalazine and auranofin treatment after 24 and 48 weeks. Life table analysis showed no significant differences in the rate of side effects which caused treatment to be stopped. Sulphasalazine works more rapidly, may be a more effective disease modifying antirheumatic drug, and is as well tolerated as auranofin.
\end{abstract}

Sulphasalazine and auranofin are established second line or disease modifying antirheumatic drugs (DMARDs) used in the treatment of rheumatoid arthritis. They have been shown in both open and double blind placebo controlled trials to exert a beneficial effect on many clinical and laboratory parameters of disease activity. ${ }^{1-4}$ There is, however, little evidence to suggest that either is preferable because of greater efficacy, more rapid effect, or lower toxicity. Such a difference would affect practical prescribing habits. Therefore a prospective, randomised comparative trial of sulphasalazine and auranofin was undertaken in a large group of patients with rheumatoid arthritis in a routine clinical environment.

Centre for

Rheumatic Diseases, Glasgow Royal Infirmary,

Castle Street, Glasgow,

United Kingdom

D Porter

R Madhok

H A Capell

Gartnavel General

Hospital, Glasgow,

United Kingdom

J A Hunter

Correspondence to:

Dr D Porter

Centre for

Rheumatic Diseases,

Glasgow Royal Infirmary, Castle Street,

Glasgow G4 OSF

United Kingdom.

Accepted for publication 30 July 1991 because of a lack of effect, or because of serious side effects (proteinuria, leucopenia or thrombocytopenia) the patient was assigned to the sulphasalazine group. If chrysotherapy had been stopped because of any other reason the the sulphasalazine group and 26 in the auranofin group had previously received intramuscular gold treatment. Twenty nine patients had previously been treated with either sulphasalazine (25) or auranofin (four) and they were assigned to receive the other drug. The remaining patients were randomised to receive either sulphasalazine or auranofin. Sulphasalazine was given at a starting dose of $500 \mathrm{mg}$ with weekly increments of $500 \mathrm{mg}$ to a target dose equivalent to $40 \mathrm{mg} / \mathrm{kg} / \mathrm{day}$ in divided doses. Auranofin was prescribed at $3 \mathrm{mg}$ twice daily; the dose was increased to $3 \mathrm{mg}$ three times a day after three months treatment if there was thought to have been a poor response to treatment. The patients, prescribing doctors, and metrologists were all aware of the identity and dose of the drug prescribed. The dose of the two drugs was altered during the trial as clinical indications dictated, either because of a poor response or because of the occurrence of side effects. Concomitant treatment with non-steroidal antiinflammatory drugs (NSAIDs) was continued.

Information was recorded about the patients' age, sex, duration of disease, and rheumatoid factor status. The patients were assessed at 0 , 12,24 , and 48 weeks for the following laboratory and clinical parameters of disease activity: Ritchie articular index, a $10 \mathrm{~cm}$ visual analogue pain scale, duration of morning stiffness, erythrocyte sedimentation rate, $\mathrm{C}$ reactive protein, and platelet count. The clinical parameters were assessed by one of two nurse metrologists and each patient was seen by the same metrologist each time; the services of the metrologists were equally distributed between the two drugs.

Where appropriate, non-parametric analysis within groups (paired Wilcoxon) and between groups (Mann-Whitney) was performed. Kolmogorov-Smirnov goodness of fit testing suggested the change in each parameter (except morning stiffness) to be normally distributed; between group analysis used Student's $t$ test with $95 \%$ confidence intervals. The rate of stopping treatment because of side effects was analysed by life table and $\chi^{2}$ analysis.

Owing to the possible bias introduced by including patients who had previously received intramuscular gold treatment, analyses of efficacy and toxicity were also performed on the subgroups of patients who had never received intramuscular gold. not excluded; if chrysotherapy had been stopped patient was randomised. Overall, $\mathbf{4 0}$ patients in

\section{Results}

There were no significant differences between the two groups in any of the demographic, 
laboratory, or clinical parameters at the start of treatment. Overall the median age of the patients 'was 56 years (sulphasalazine 55 , auranofin 57 , range $20-82$ years), with a median disease duration of nine years (sulphasalazine 10 , auranofin nine, range $0-42$ years). One hundred and sixty eight of the 200 patients were women and $72 \%$ were seropositive for rheumatoid factor at a titre of $1 / 64$ (Rose Waaler). The median dose of sulphasalazine was $2.5 \mathrm{~g} /$ day (range $1.5-4.0 \mathrm{~g} /$ day). Twenty one per cent of the auranofin group had the dose of their auranofin increased to $3 \mathrm{mg}$ three times a day at week 12. Eighty two sulphasalazine and 79 auranofin patients completed 12 weeks of treatment, 76 sulphasalazine and 71 auranofin patients completed 24 weeks of treatment, and 63 sulphasalazine and 50 auranofin patients continued treatment for more than 48 weeks. Two auranofin patients died, one from ischaemic

heart disease (week 15) and one from congestive cardiac failure secondary to rheumatic heart disease (week 16). Three auranofin and two sulphasalazine patients were lost to follow up before their 48 week assessment because of noncompliance or moving away from the area.

There was a significant improvement between 0 and 12 weeks for all parameters in the sulphasalazine group, and for all except the articular index in the auranofin group. Between 0 and 24, and 0 and 48 weeks, all parameters improved significantly in both groups. By 12 weeks, however, the sulphasalazine group had a significantly lower erythrocyte sedimentation rate (Mann Whitney, $p=0.04$ ), platelet count $(p=0.009)$, and articular index $(p=0.04)$ (table 1 and fig 1 ). There was a significantly larger reduction in erythrocyte sedimentation rate and $C$ reactive protein in the sulphasalazine group between 0 and 12 weeks compared with the

Table 1 Median (range) of all parameters at weeks $0,12,24$, and 48

\begin{tabular}{|c|c|c|c|c|c|}
\hline Parameter & Drug treatment & Week 0 & Week 12 & Week 24 & Week 48 \\
\hline $\begin{array}{l}\text { Erythrocyte sedimentation } \\
\text { rate }(\mathrm{mm} / \mathrm{h})\end{array}$ & $\begin{array}{l}\text { Sulphasalazinet } \\
\text { Auranofinf } \\
\text { Mann-Whitney }\end{array}$ & $\begin{array}{l}51(2-136) \\
52(2-150) \\
\text { NS }\end{array}$ & $\begin{array}{l}28(1-124)^{* *} \\
36(2-138)^{*} \\
p=0.04\end{array}$ & $\begin{array}{l}24(3-133)^{* *} \\
30(4-136)^{* * *} \\
\text { NS }\end{array}$ & $\begin{array}{l}30(1-128)^{* * *} \\
29(3-110)^{* * *} \\
\text { NS }\end{array}$ \\
\hline $\mathrm{C}$ reactive protein $(\mathrm{mg} / \mathrm{l})$ & $\begin{array}{l}\text { Sulphasalazine } \\
\text { Auranofin } \\
\text { Mann-Whitney }\end{array}$ & $\begin{array}{l}40(10-170) \\
37(10-173) \\
\text { NS }\end{array}$ & $\begin{array}{l}17(10-171)^{* * *} \\
20(10-182)^{*} \\
\text { NS }\end{array}$ & $\begin{array}{l}11(7-205)^{* *} \\
16(10-135)^{* * *} \\
\text { NS }\end{array}$ & $\begin{array}{l}17(8-100)^{* * *} \\
17(3-245)^{* *} \\
\text { NS }\end{array}$ \\
\hline Platelets $\left(\times 10^{9} / 1\right)$ & $\begin{array}{l}\text { Sulphasalazine } \\
\text { Auranofin } \\
\text { Mann-Whitney }\end{array}$ & $\begin{array}{l}415(203-739) \\
427(116-924) \\
\text { NS }\end{array}$ & $\begin{array}{l}336(178-869)^{* * *} \\
385(158-890)^{*} \\
p=0.009\end{array}$ & $\begin{array}{l}333(171-804)^{* * *} \\
358(135-756)^{* * *} \\
\text { NS }\end{array}$ & $\begin{array}{l}324(155-624)^{*: *} \\
364(178-709)^{* * *} \\
\text { NS }\end{array}$ \\
\hline Articular index & $\begin{array}{l}\text { Sulphasalazine } \\
\text { Auranofin } \\
\text { Mann-Whitney }\end{array}$ & $\begin{array}{l}11(0-45) \\
14(0-44) \\
\text { NS }\end{array}$ & $\begin{array}{l}8(0-48)^{*} \\
12(0-49) \\
p=0 \cdot 04\end{array}$ & $\begin{array}{l}5(0-38)^{*} \\
\quad 6(0-39)^{*} \\
\text { NS }\end{array}$ & $\begin{array}{l}6(0-37)^{* * *} \\
3(0-34)^{* * *} \\
\text { NS }\end{array}$ \\
\hline Early morning stiffness & $\begin{array}{l}\text { Sulphasalazine } \\
\text { Auranofin } \\
\text { Mann-Whitney }\end{array}$ & $\begin{array}{l}90(0-720) \\
120(0-720) \\
\text { NS }\end{array}$ & $\begin{array}{l}60(0-720)^{*} \\
60(0-720)^{*} \\
\text { NS }\end{array}$ & $\begin{array}{l}30(0-720)^{* * *} \\
15(0-720)^{* * *} \\
\text { NS }\end{array}$ & $\begin{array}{l}30(0-720)^{* * *} \\
15(0-720)^{* * *} \\
\text { NS }\end{array}$ \\
\hline Pain score & $\begin{array}{l}\text { Sulphasalazine } \\
\text { Auranofin } \\
\text { Mann-Whitney }\end{array}$ & $\begin{array}{l}55(0-100) \\
64(0-100) \\
\text { NS }\end{array}$ & $\begin{array}{l}40(0-100)^{* * *} \\
50(0-100)^{*} \\
\text { NS }\end{array}$ & $\begin{array}{l}35(0-100)^{* *} \\
45(0-100)^{* *} \\
\text { NS }\end{array}$ & $\begin{array}{l}43(0-100)^{* * *} \\
33(0-100)^{\text {*:* }} \\
\text { NS }\end{array}$ \\
\hline
\end{tabular}

Within groups paired Wilcoxon ${ }^{*} \mathrm{p}<0.05,{ }^{* *} \mathrm{p}<0.0001$.

tSulphasalazine: week $0, n=100$; week 12, $n=82$; week $24, n=76$; week $48, n=63$

†Auranofin: week $0, n=100$; week $12, n=79$; week $24, n=71$; week $48, n=50$.

Figure 1 Median erythrocyte sedimentation rate $(E S R), C$ reactive protein $(C R P)$, platelet count, and articular index at weeks $0,12,24$, and 48 .
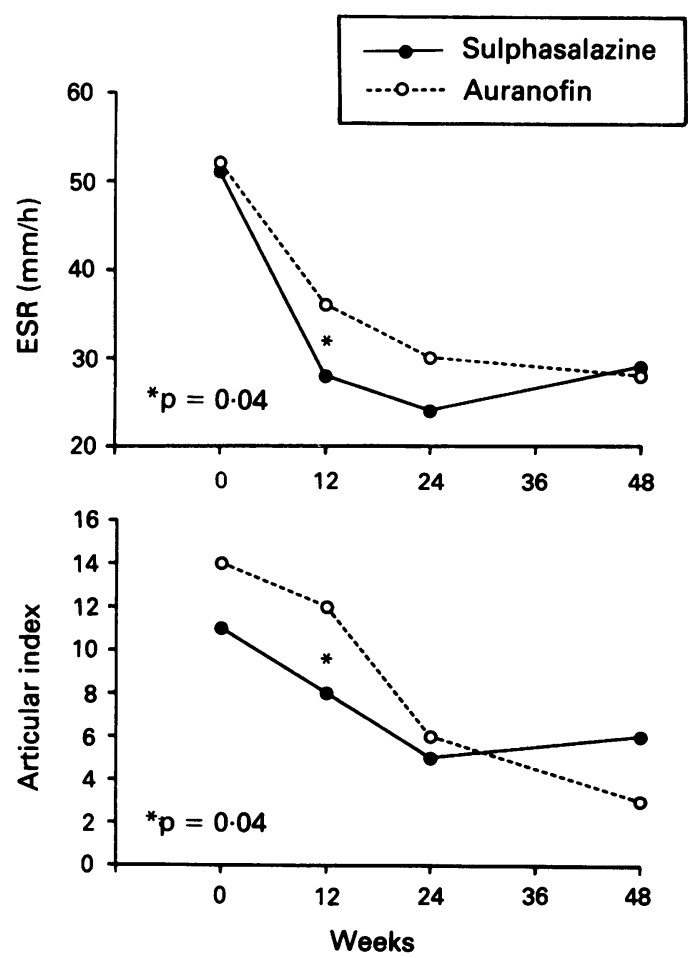
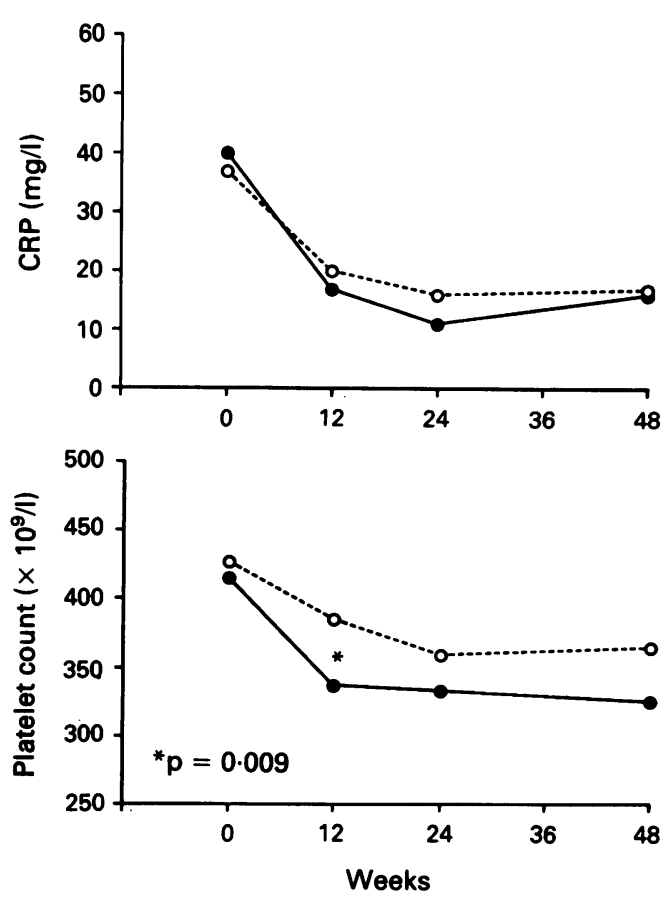
Figure 2 Mean change in erythrocyte sedimentatio rate $(E S R), C$ reactive protein $(C R P)$, platelet count, and articular index with $95 \%$ confidence intervals.
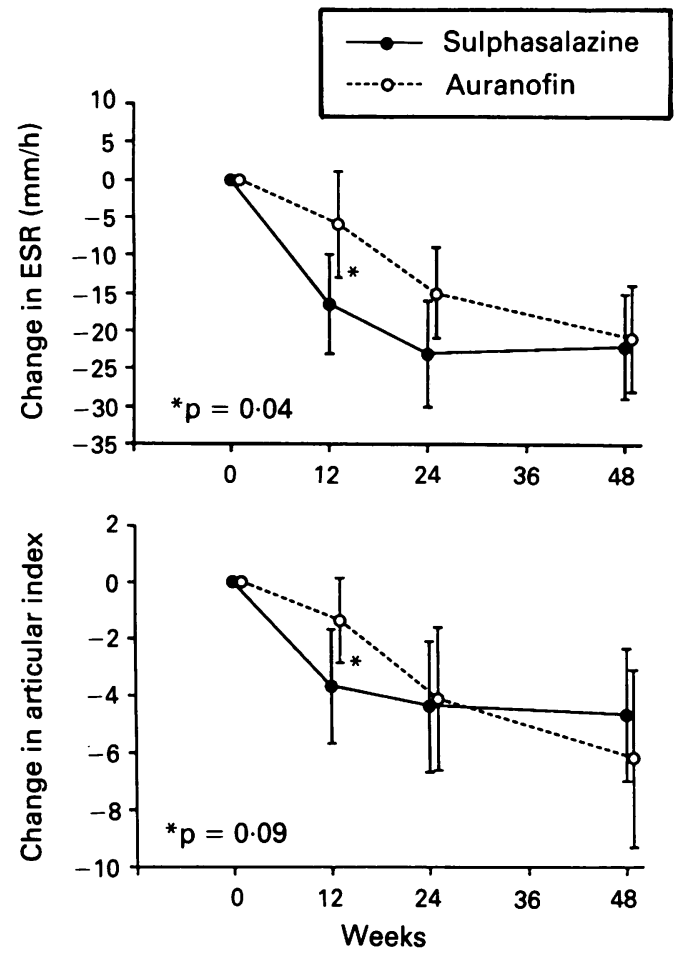

auranofin group (fig 2). Between group analysis at 24 and 48 weeks showed there were no longer significant differences between the groups.

After exclusion of the patients previously treated with intramuscular gold, there was still significantly more improvement with sulphasalazine between 0 and 12 weeks in the erythrocyte sedimentation rate $(p=0.04)$ and $C$ reactive protein $(p=0.03)$, and the decrease in articular index and visual analogue pain scale now also reached significance (both $\mathrm{p}<0.05$ ). There were still no significant differences between the groups in the improvement in variables between 0 and 24 , and 0 and 48 weeks.

Following the week 48 assessment, 28/100 sulphasalazine and $37 / 100$ auranofin patients had stopped treatment because of side effects (table 2). Seven sulphasalazine and eight auranofin patients discontinued treatment because of a lack or loss of effect. In the auranofin group, a significantly greater discontinuation rate was seen in the patients previously treated with intramuscular gold (19/26), compared with those who had not $\left(31 / 74 ; \chi^{2}\right.$ $7 \cdot 68, \mathrm{p}<0.01)$. In the sulphasalazine group, the discontinuation rate was not significantly different in the patients who had previously

Table 2 Outcome at one year

\begin{tabular}{|c|c|c|}
\hline Outcome & Sulphasalazine & Auranofin \\
\hline Still receiving treatment $(\%)$ & 63 & 50 \\
\hline Lack or loss of effect (\%) & 7 & 8 \\
\hline Side effects (\%) & 28 & 37 \\
\hline Diarrhoea & 3 & 19 \\
\hline Nausea/vomiting & 6 & 1 \\
\hline \multicolumn{3}{|l|}{ Central nervous system } \\
\hline (headache, etc) & 2 & 2 \\
\hline Rash & 5 & $\overline{7}$ \\
\hline Itch & 1 & \\
\hline Mouth ulcers & 2 & 2 \\
\hline Leucopenia & 6 & 2 \\
\hline Thrombocytopenia & & $\overline{1}$ \\
\hline Abnormal LFTs & 2 & \\
\hline Proteinuria & & 2 \\
\hline Other & 1 & 2 \\
\hline $\operatorname{Died}(\%)$ & 0 & 2 \\
\hline Lost to follow up (\%) & 2 & 3 \\
\hline
\end{tabular}
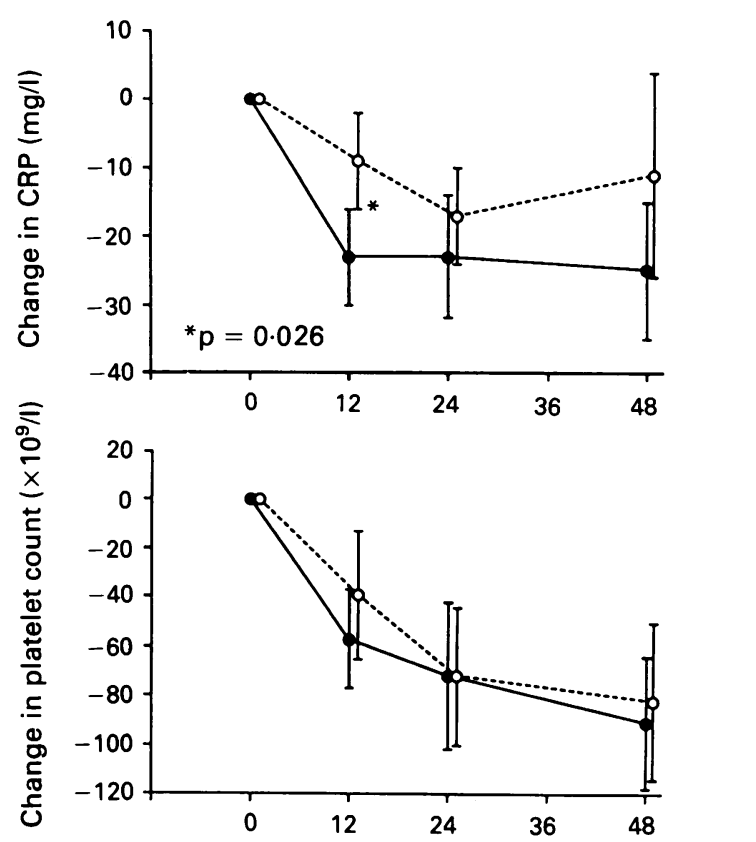

received intramuscular gold (18/40 compared with $\left.19 / 60, \chi^{2} 1 \cdot 3, p=N S\right)$. Comparing the sulphasalazine and auranofin groups, life table analysis showed no significant difference in the rate of stopping treatment between groups; once the patients who had previously received gold were excluded from the auranofin group the overall discontinuation rates were very similar $-37 \%$ with sulphasalazine and $42 \%$ with auranofin. The side effects encountered were as expected. During auranofin treatment the most common side effect was diarrhoea, whereas during sulphasalazine treatment upper gastrointestinal symptoms and headache predominated. Six sulphasalazine and one auranofin patient developed leucopenia, and one auranofin patient developed leucopenia and thrombocytopenia. There was a prompt recovery in all patients on stopping treatment. The decrease in the white cell count occurred in the first three months in four patients, between three and six months in three patients and after 48 weeks in one patient, emphasising the need to continue monitoring these patients carefully throughout treatment. There was no other serious or life threatening side effects.

\section{Discussion}

Sulphasalazine and auranofin are widely prescribed as second line drugs in the treatment of rheumatoid arthritis. There is little evidence, however, about their relative efficacy. An assessment of drug efficacy must take into account several factors, including the magnitude and rate of the response, the percentage of patients responding, and the percentage of patients not tolerating the drug treatment long term because of side effects.

Sulphasalazine and auranofin have been shown to be effective in open and double blind placebo controlled trials. ${ }^{1-4}$ The two drugs have been compared to penicillamine and are said to be of similar efficacy. All the trials 
however, have been small or have relied on indirect measures of efficacy (such as the number of patients receiving long term treatment). 56

Ward et al showed both intramuscular gold and auranofin to be superior to placebo, and of similar efficacy. ${ }^{7}$ An earlier decrease in the platelet count and increase in haemoglobin with intramuscular gold treatment, however, suggested a more rapid effect with parenteral treatment. ${ }^{7}$ Capell et al found a higher percentage of patients stopping auranofin treatment compared with intramuscular gold because of a lack of effect. More than $50 \%$ of patients stopping auranofin treatment for this reason subsequently responded to intramuscular gold. ${ }^{8}$ This implies that intramuscular gold is a more potent DMARD than auranofin. Comparing sulphasalazine and intramuscular gold, some studies have found no evidence for a difference in efficacy, ${ }^{9}$ whereas others have suggested that intramuscular gold may be more potent; for instance, more patients obtaining a 'good response' rather than a 'partial response' with intramuscular gold. ${ }^{10}$

Including patients previously treated with intramuscular gold introduced a source of possible bias. Patients for whom intramuscular gold treatment had previously failed could have more severe disease, introducing a bias against the sulphasalazine group; alternatively it could be argued that the failure of treatment with intramuscular gold (for whatever reason) would mean that the patients were unlikely to respond to another gold compound, introducing a bias against the auranofin group. The former seems more likely, because subgroup analysis after the exclusion of the patients previously treated with intramuscular gold confirmed the superiority of sulphasalazine over auranofin at 12 weeks, and the greater response was statistically significant in more parameters than in the analysis of the whole groups.

This study shows a greater response to sulphasalazine compared with auranofin at 12 weeks. This suggests either a more rapid response or a greater effect with sulphasalazine. As the differences between the two groups had reduced by week 24 , and had disappeared by 48 weeks, the former is more likely. Although not statistically significant for most parameters at week 24 , however, the trend still suggested a greater response to sulphasalazine. It may be that sulphasalazine has a greater as well as a more rapid effect and that by 48 weeks the two patient groups had become highly selected because of substantial discontinuation rates. This trial used multiple comparisons and it is possible that the differences observed occurred by chance. All the significant differences occurred after 12 weeks, however, and all were in favour of sulphasalazine. There were three significant results out of 18 hypotheses tested by the Mann-Whitney between group analysis, and this is more than is expected by chance as a result of multiple comparisons.

A previous comparative study of sulphasalazine and penicillamine by this centre showed a median percentage improvement in the erythrocyte sedimentation rate of $42 \%$ at one year and $45 \%$ at two years with sulphasalazine. ${ }^{11}$ This is similar to the $50 \%$ improvement seen in this study at six months (data not shown). This lends weight to the clinical impression that the maximum effect from sulphasalazine is achieved by six months.

The number of patients still receiving treatment after several years is a useful index of efficacy and the rate of unacceptable side effects. Some workers have found that more patients are still receiving sulphasalazine after two years compared with intramuscular gold. ${ }^{12}$ In a trial of patients with early rheumatoid arthritis, Johnsen found that $50 \%$ of patients were still receiving treatment with auranofin after two years, which compares favourably with results previously published for intramuscular gold, penicillamine, and sulphasalazine. In that study, however, 24/65 patients were also still receiving placebo at two years, suggesting this was a study of patients with particularly mild disease. ${ }^{2}$ The trial reported here suggests that sulphasalazine is as well tolerated as auranofin during the first year of treatment. It is also clear that the use of auranofin in patients who have stopped treatment with intramuscular gold because of side effects is inadvisable, with an extremely high rate of discontinuation of treatment.

Sulphasalazine treatment may be preferable to auranofin because of a faster, and possibly greater, effect, with no attendant increased toxicity. If auranofin is used, a clinical response may not be apparent until 24 weeks; if possible, treatment should not be stopped before 24 weeks because of a lack of effect.

We thank Smith, Kline, and French for starter packs of auranofin and sulphasalazine; Anne Thomson and Marion Morrison for metrology; Dorothy McKnight for computing help Morrison for metrology; Dorothy McKnight for computing help
and statistical analysis; and Ann Tierney for typing the manuscript.

1 Finkelstein A, Walz D, Batista V, et al. New oral gold compound for treatment of rheumatoid arthritis. Ann Rheum Dis 1976; 35: 251-7.

2 Johnsen V, Borg G, Trang L, Berg E, Brodin U. Auranofin in early rheumatoid arthritis: results from a 24 month double blind placebo controlled study. Scand $\mathcal{7}$ Rheumato 1989; 18: 251-60.

3 McConkey B, Amos R, Durham S, Forster P, Hubball S Walsh L. Sulphasalazine in rheumatoid arthritis. $B M \mathcal{J}$ 1980; 280: 442-4.

4 Pullar T, Hunter J, Capell $H$. Sulphasalazine in rheumatoid arthritis: a double blind comparison of sulphasalazine with placebo and sodium aurothiomalate. $B M \mathcal{F} 1983 ; 287$

5 Farr M, Tunn E, Crockson A, Bacon P. Long term effects of sulphasalazine in the treatment of rheumatoid arthritis and a comparative study with penicillamine. Clin Rheumatol a comparative st 4 : 473-82.

6 Manthorpe R, Horbov S, Sylvest J, Vinterberg H. Auranofin versus penicillamine in rheumatoid arthritis. Scand $\mathcal{f}$ Rheumatol 1986; 15: 13.

7 Ward J, Williams $\mathrm{H}$, Egger $\mathrm{M}$, et al. Comparison of auranofin, gold sodium thiomalate, and placebo in the treatment of rheumatoid arthritis: a controlled clinical trial. Arthritis Rheum 1983; 26: 1303-15.

8 Capell H, Lewis D, Carey J. A three year follow-up of patients allocated to placebo, or oral or injectable gold therapy for rheumatoid arthritis. Ann Rheum Dis 1986; 45 $705-11$.

9 Williams H, Ward J, Dahl S, et al. A controlled trial comparing sulphasalazine, gold sodium thiomalate and
placebo in rheumatoid arthritis. Arthritis Rheum 1988; 31:
$702-13$.

0 Bax D, Amos R. Sulphasalazine: a safe effective agent for prolonged control of rheumatoid arthritis: a comparison
with sodium aurothiomalate. Ann Rheum Dis 1985; 44:

11 Capell H A, Marabani M, Madhok R, Torley H, Hunter J A. Degree and extent of response to sulphasalazine or penicillamine therapy for rheumatoid arthritis: results from a routine clinical environment over a two-year period. $Q \mathcal{J}$
Med 1990; 75: 276: 335-44.

12 Situnayake R, McConkey B. Long term outcome of treatment with sulphasalazine in rheumatoid arthritis. Drug 1986; 32 (suppl): 71-2. 